\title{
Methods of Intracanal Reinforcement in Primary Anterior Teeth-Assessing the Outcomes through a Systematic Literature Review
}

\author{
${ }^{1}$ Neeti Mittal, ${ }^{2}$ Hind Pal Bhatia, ${ }^{3}$ Khushtar Haider
}

\begin{abstract}
Aim: To assess how the various methods of intracanal reinforcement (short root canal posts) performed in their clinical and radiographic outcomes for restoring grossly broken down primary anterior teeth after pulpectomy for 1 year or longer follow-up period.
\end{abstract}

Materials and methods: Literature search of electronic databases (Sept 2013) and various journals (1980-Sept 2013) using medical subject headings and free text terms was conducted. For inclusion in quality assessment, prespecified inclusion criteria were applied. Quality assessment was performed by using 'The Cochrane collaboration's tool for assessing risk of bias'.

Results: Seven relevant papers were selected for full text evaluation. After applying the inclusion criteria, only two trials could be considered for quality assessment. Both of these were classified as having high risk of bias.

Conclusion: The evidence to support any method of intracanal reinforcement for restoring grossly broken down anterior teeth is presently lacking. Further trials with well-defined methodology are needed.

Keywords: Evidence, Intracanal reinforcement, Posts, Primary teeth, Restorations.

How to cite this article: Mittal N, Bhatia HP, Haider K. Methods of Intracanal Reinforcement in Primary Anterior TeethAssessing the Outcomes through a Systematic Literature Review. Int J Clin Pediatr Dent 2015;8(1):48-54.

Source of support: Nil

Conflict of interest: None

\section{INTRODUCTION}

The phenomenal developments in the field of preventive dentistry have worked wonders to cause a remarkable

\footnotetext{
${ }^{1}$ Assistant Professor, ${ }^{2}$ Professor and Head

${ }^{3}$ Postgraduate Student

${ }^{1,3}$ Department of Pedodontics and Preventive Dentistry Santosh Dental College, Ghaziabad, Uttar Pradesh, India

${ }^{2}$ Department of Pedodontics and Preventive Dentistry, Manav Rachna Dental College, Faridabad, Haryana, India

Corresponding Author: Neeti Mittal, Assistant Professor Department of Pedodontics and Preventive Dentistry, Santosh Dental College, Ghaziabad, Uttar Pradesh, India, e-mail: dr.neetipgi@gmail.com
}

decline in prevalence of dental caries globally., But, yet, there remains a section of young population from developed as well as developing countries who present as high caries risk subjects. ${ }^{3}$ It is not very uncommon to see young patients with multiple grossly decayed anterior as well as posterior primary teeth. Restoring primary teeth is important not only for mastication, speech, alveolar growth and harmonious stomatomusculoskeletal system, but also for psychological well-being of the child. Restoring grossly carious primary teeth is challenging compared to permanent teeth which have greater bulk of tooth structure to offer promising retention for restorations. Pulpal involvement in primary teeth is faster and endodontic intervention further leaves very little tooth structure. It is very common to see primary anterior teeth with complete coronal destruction. To prepare these mutilated primary anterior teeth to receive complete coronal restorations, retention is gained from short intracanal posts.

Gaining intracanal retention for restoring mutilated anterior teeth is tricky compared to permanent teeth not only because of little remaining tooth structure; but also because of the fact that primary teeth have to make way for their permanent counterparts. The intracanal posts should shed in a timely manner to allow unimpeded timely eruption of their permanent successors in normal undeflected positions. Other much needed characteristics of intracanal posts for primary teeth are biocompatibility, ease of availability and applicability, esthetics and ability to withstand masticatory forces.

A multitude of methods have been used for intracanal reinforcement for anterior teeth, such as short composite posts, ${ }^{4,5}$ short wire posts (omega loop), ${ }^{6-10} \mathrm{Ni}-\mathrm{Cr}$ coil spring posts, ${ }^{11}$ readymade glass fiber posts,,${ }^{9,12-15}$ polyethylene fibre post/ribbond ${ }^{16-21}$ and metal screw posts. ${ }^{22,23}$ The crown anatomy can be restored by direct composite build up by incremental method, ${ }^{6,8,16,20,22}$ composite build-up using celluloid strip crowns, $, 7,7,14,18,19,23$ composite build-up by indirect technique ${ }^{11,12,17,24}$ and biological shell crowns. ${ }^{8,25}$

Owing to heterogeneity of available data on intracanal posts, the pediatric dentists might encounter difficulty in having an evidence-based choice of intracanal posts in 
clinical situations. Keeping this in mind, it was decided to perform a systematic review to assess the quality of evidence for methods of intracanal reinforcement for grossly broken down primary anterior teeth. Our primary study objective was to assess how the various methods of intracanal reinforcement (short root canal posts) performed (in their clinical and radiographic outcomes) for restoring grossly broken down primary anterior teeth after pulpectomy in a follow-up period of 1 year or more.

\section{MATERIALS AND METHODS}

Search strategy: The literature studying the 'methods of intracanal reinforcement' for restoring grossly decayed primary anterior teeth was reviewed by Neeti Mittal (NM) and Khushtar Haider (KH) independently and in duplication. In addition to electronic databases, hand search was also performed for some journals (Table 1). Controlled vocabulary using $\mathrm{MeSH}$ terms and combination of free text terms was used (Table 1). Following databases were searched: PubMed (till Sept 2013), Scopus (till Sept 2013) and Cochrane library (till Sept 2013). Search strategy was developed for PubMed and was modified appropriately for other databases. There were no language restrictions and no filters were activated. Titles and abstracts were assessed by NM and $\mathrm{KH}$ independently for inclusion in this review. In case of any doubt, consensus was arrived at by seeking opinion of Hind Pal Bhatia (HB).

Selection criteria: For full text evaluation, references were selected by reviewing titles and abstracts by NM and $\mathrm{KH}$ independently and in duplication. Descriptive data extraction was performed for all identified prospective clinical trials studying the clinical and radiographic outcomes of intracanal reinforcement for restoring grossly broken down primary anterior teeth after pulpectomy. After descriptive data extraction, inclusion criteria for consideration in qualitative systematic review were applied. These inclusion criteria were: prospective randomized controlled clinical trial, clinical and radiographic performance of intracanal posts for restoring grossly decayed primary anterior teeth as outcome measure, follow-up period of 1 year or more. Case reports and in vitro trials were not included.

Data extraction: Data were extracted by NM for 7 items, i.e. author, year, sample, groups, evaluation criteria, results and author's conclusions. In case of missed data, corresponding authors were contacted for gathering necessary information.

Quality assessment and risk of bias: Quality assessment was performed only after applying the prespecified inclusion criteria. It was done independently and in duplication by NM and KH. Doubts were resolved by consensus of all three authors.

Quality assessment was done using a modified version of 'The Cochrane Collaboration's tool for assessing risk of bias. ${ }^{26}$ Risk of bias was evaluated for following domains, i.e. selection bias, performance bias, detection bias, attrition bias, reporting bias and miscellaneous. Multiple parameters were used to assess these domains (Table 2). Risk of bias was calculated as high risk, low risk or unclear risk of bias as per recommendations provided in online version of Cochrane handbook for systematic reviews of interventions (version 5.1.0; updated on March 2011). ${ }^{26}$ Overall risk of bias for individual study was

Table 1: Literature search strategy and outcomes

\begin{tabular}{|c|c|c|c|c|c|c|c|}
\hline Search method & Search term/journal name & $\begin{array}{l}\text { Number } \\
\text { of items } \\
\text { retrieved }\end{array}$ & $\begin{array}{l}\text { Number of } \\
\text { items related } \\
\text { to study } \\
\text { outcome }\end{array}$ & $\begin{array}{l}\text { Items not } \\
\text { found during } \\
\text { PubMed } \\
\text { search }\end{array}$ & $\begin{array}{l}\text { Case } \\
\text { reports }\end{array}$ & $\begin{array}{l}\text { In vitro } \\
\text { studies }\end{array}$ & $\begin{array}{l}\text { Number of } \\
\text { relevant items } \\
\text { (in vivo } \\
\text { clinical trials) }\end{array}$ \\
\hline PubMed search & $\begin{array}{l}\text { Intracanal post and primary } \\
\text { not permanent teeth }\end{array}$ & 10 & 6 & NA & 2 & 2 & 2 \\
\hline PubMed search & $\begin{array}{l}\text { Canal and post and primary } \\
\text { not permanent teeth }\end{array}$ & 61 & 11 & NA & 6 & 3 & 2 \\
\hline PubMed search & $\begin{array}{l}\text { Restoration and anterior teeth and } \\
\text { primary not permanent teeth }\end{array}$ & 69 & 10 & NA & 6 & 2 & 2 \\
\hline Scopus & $\begin{array}{l}\text { Restoration and anterior teeth and } \\
\text { primary teeth }\end{array}$ & 154 & 12 & 2 & 6 & 1 & 5 \\
\hline Cochrane library & $\begin{array}{l}\text { Restoration and anterior teeth and } \\
\text { primary not permanent teeth }\end{array}$ & 2 & 0 & 0 & 0 & 0 & 0 \\
\hline Hand search & $\begin{array}{l}\text { International Journal of Pediatric } \\
\text { Dentistry }\end{array}$ & NA & 1 & 0 & 1 & 0 & 0 \\
\hline Hand search & Journal of Clinical Pediatric Dentistry & NA & 9 & 1 & 3 & 3 & 3 \\
\hline Hand search & Journal of Dentistry for Children & NA & 1 & 1 & 1 & 0 & 0 \\
\hline Hand search & Pediatric Dentistry & NA & 0 & 0 & 0 & 0 & 0 \\
\hline Hand search & $\begin{array}{l}\text { Journal of American Dental } \\
\text { Association }\end{array}$ & NA & 1 & 1 & 0 & 0 & 1 \\
\hline Total & & - & - & - & 15 & 5 & 7 \\
\hline
\end{tabular}


calculated as per prespecified criteria. If all parameters were reported to have low risk of bias, the study was said to have low risk of bias. If one parameter was reported to have high risk of bias, the study was said to have moderate risk of bias. If one parameter was reported to have unclear risk of bias, the study was said to have unclear risk of bias. Further, any study was considered to have high risk of bias if $\geq 2$ parameters had unclear and/or high risk of bias.

\section{RESULTS}

Out of a total of 27 references retrieved, 15 case reports and 5 in vitro trials were excluded from full text evaluation. A total of 7 in vivo clinical trials were identified for data extraction (Table 3).

Quality assessment: Only two trials ${ }^{8,9}$ were considered for quality assessment as 5/7 clinical trials were excluded (Table 4). Reasons for exclusion are given in Table 4. Out of a total of 12 parameters evaluated, high risk of bias was reported for nine parameters in trial reported by Subramaniam et al. ${ }^{9}$ The same was the case for trial reported by Grewal and Seth, ${ }^{8}$ where a total of six parameters were found to have high risk of bias (Table 5). Hence, the overall risk of bias assigned to both of these trials was 'high'.

Meta-analysis: Data could not be pooled to perform meta-analysis as only limited number of heterogeneous studies could be included in this systematic review. Further, the evidence generated from these two studies was also poor as both were classified as having high risk of bias.

\section{DISCUSSION}

The evidence to base any recommendation could not be gathered in present systematic review owing to small number (only 2) of poor quality randomized trials. ${ }^{8,9}$

Table 2: Assessing the risk of bias: domains and parameters

\begin{tabular}{|c|c|}
\hline Domain & Parameters \\
\hline \multirow[t]{4}{*}{ Selection bias } & 1. Definition of inclusion criteria \\
\hline & 2. Definition of exclusion criteria \\
\hline & 3. Random sequence generation \\
\hline & 4. Allocation concealment \\
\hline $\begin{array}{l}\text { Performance } \\
\text { bias }\end{array}$ & Adequate blinding \\
\hline Detection bias & Blinding of outcome assessor \\
\hline Attrition bias & Reporting of dropouts \\
\hline Reporting bias & Incomplete outcome reporting \\
\hline \multirow[t]{3}{*}{ Miscellaneous } & $\begin{array}{l}\text { 1. Elaboration of clinical assessment } \\
\text { methods and parameters }\end{array}$ \\
\hline & $\begin{array}{l}\text { 2. Elaboration of radiographic assessment } \\
\text { methods and parameters }\end{array}$ \\
\hline & 3. Adequate follow-up period \\
\hline
\end{tabular}

In order to generate quality evidence, the trials should have adequate inclusion and exclusion criteria, i.e. adequate definition of clinical and radiographic conditions, e.g. amount of remaining tooth structure (as this is important to support post and subsequent crown) and/ or mobility and/or remaining root length. In addition to this, another very important factor to ensure baseline equivalence, randomization should be ensured via random sequence generation and allocation concealment. ${ }^{27-30}$ None of these measures were incorporated in selected trials and, thus, these studies were flawed with selection bias. Blinding is important to avoid detection bias in a trial. ${ }^{27,29,30}$ In both of the selected studies, no statements were made regarding blinding. Blinding of participants should be done; however, blinding of operator, in such trials is not feasible owing to clear distinction between different types of posts as well as obvious differences in clinical techniques. Instead, blinding of outcome assessor should be done. ${ }^{29,30}$ In addition to type of posts and/or techniques, the outcome assessor should also be additionally blinded to time period of evaluation, e.g. immediate follow-up or 6 months, 12 months and so on. Another methodological flaw with selected studies was lack of information about drop outs, if any. Drop outs in any clinical study can disrupt the baseline equivalence amongst study groups. ${ }^{26}$ Postoperative evaluation at multiple time intervals should be done using prespecified clinical and radiographic criteria. These criteria should be able to evaluate the success of material as well as technique. Both of these studies used prespecified criteria, but criteria used by Subramaniam et $\mathrm{al}^{9}$ did not include any radiographic measures. Also, the clinical criteria used by them were neither sufficient nor validated. Ideally, such trials should have a follow-up period to allow observation of normal exfoliation and eruption of permanent successors. But, this is always not feasible. A follow-up period of sufficiently long duration to reasonably prove the successful performance in oral cavity for predefined clinical and radiographic criteria can serve as a proxy for this. In this systematic review, a follow-up period of 1 year was considered to be sufficient.

A reliable way to ensure quality in clinical randomized trials to generate quality evidence is to follow, 'The Cochrane Collaboration's tool for assessing risk of bias ${ }^{26}$ and 'CONSORT statement'. ${ }^{31}$

As the evidence to support any of the material and/ or technique was found to be deficient, a narrative discussion is provided below to guide pediatric dentists to select a suitable method of intracanal reinforcement in commonly encountered clinical problems.

Short composite posts: Short composite posts are easy to apply and exhibit excellent esthetics because of 
Table 3: Data extraction from in vivo clinical trials

\begin{tabular}{|c|c|c|c|c|c|}
\hline Author/year & Sample & Groups & Evaluation criteria & Results & Author's conclusion \\
\hline $\begin{array}{l}\text { Judd PL et al } \\
1990^{5}\end{array}$ & $\begin{array}{l}\mathrm{N}=92 \\
\text { teeth }\end{array}$ & $\begin{array}{l}\text { Short composite } \\
\text { post with } \\
\text { composite resin } \\
\text { crown }\end{array}$ & $\begin{array}{l}\text { Marginal integrity, } \\
\text { mobility, caries } \\
\text { at the composite } \\
\text { resin-tooth } \\
\text { margin and } \\
\text { fractures at } 6 \text { and } \\
12 \text { months }\end{array}$ & $\begin{array}{l}\text { Four teeth in two patients showed recurrent } \\
\text { caries at the composite resin-tooth cervical } \\
\text { margin. Three of these teeth were restored } \\
\text { and one was extracted. Three crowns } \\
\text { showed incisal fracture of minimal severity. } \\
\text { These were later rebuilt with a resin add on } \\
\text { technique. Four crowns displayed severe } \\
\text { attrition in one patient who was a severe } \\
\text { bruxer. }\end{array}$ & $\begin{array}{l}\text { Short posts were } \\
\text { retentive. Recurrent } \\
\text { caries and severe } \\
\text { bruxism-factors } \\
\text { beyond operator } \\
\text { control-posed some } \\
\text { problems that were } \\
\text { readily resolved. }\end{array}$ \\
\hline $\begin{array}{l}\text { Sharaf AA } \\
2002^{15}\end{array}$ & $\begin{array}{l}\mathrm{N}=12 \\
\text { Age }=4 \\
\text { years }\end{array}$ & $\begin{array}{l}\mathrm{N}=30 \text { teeth } \\
\text { Fiber glass post } \\
\text { with celluloid strip } \\
\text { crown }\end{array}$ & $\begin{array}{l}\text { Color match, } \\
\text { marginal } \\
\text { adaptation, } \\
\text { marginal } \\
\text { discoloration, } \\
\text { anatomic form, }\end{array}$ & $\begin{array}{l}28 / 30 \text { teeth performed well. Failure in } \\
\text { pulp treatment rather than failure of the } \\
\text { restoration itself was reported in } 2 / 30 \\
\text { teeth. }\end{array}$ & $\begin{array}{l}\text { This technique } \\
\text { significantly improved } \\
\text { the fracture load } \\
\text { resistance of } \\
\text { composite celluloid } \\
\text { crown. }\end{array}$ \\
\hline
\end{tabular}

$\begin{array}{lll}\text { Mortada A, } & \mathrm{N}=25 & \mathrm{~N}=96 \text { teeth } \\ \text { King NM } & \text { Age }=38 & \begin{array}{l}\text { Omega-shaped } \\ \text { wire post with } \\ \text { months }\end{array} \\ & & \begin{array}{l}\text { compomer } \\ \text { com }\end{array}\end{array}$

Grewal N, Seth R 2008

$\mathrm{N}=32$

Age $=$

3-5

years crown secondary caries, gingival condition, pain, temperature sensitivity and periapical condition at 3, 6, 9 and 12 months

Retention, recurrent caries and the presence of any periapical radiolucency at 3 , 6,12 and 18 months

Group $1(\mathrm{n}=75)$ : Biologic post and

Group $2(\mathrm{n}=75)$ : short composite post

\section{Modified USPHS}

system applied every $0,3,6,9$ and 12 months

\begin{tabular}{|c|c|c|}
\hline Subramaniam & $N=10$ & Group $1(n=14)$ \\
\hline$P$ et al $2008^{9}$ & $\begin{array}{l}\text { Age }= \\
3-4 \\
\text { years }\end{array}$ & $\begin{array}{l}\text { Fiber glass post } \\
\text { with celluloid strip } \\
\text { crowns } \\
\text { Group } 2 \text { ( } n=14 \text { ) } \\
\text { Omega-wire pos } \\
\text { with celluloid strip } \\
\text { crowns }\end{array}$ \\
\hline $\begin{array}{l}\text { Aminabadi } \\
\text { NA, Farahani } \\
\text { RM } 2009^{10}\end{array}$ & $\begin{array}{l}\mathrm{N}=60 \\
\mathrm{Age}= \\
3-4 \\
\text { years }\end{array}$ & $\begin{array}{l}\mathrm{N}=144 \text { teeth } \\
\text { Omega-shaped } \\
\text { wire post with } \\
\text { compomer }\end{array}$ \\
\hline
\end{tabular}

$\begin{array}{lll}\text { Memarpour } & \mathrm{N}=24 & \mathrm{~N}=55 \text { teeth } \\ \mathrm{M}, \text { Shafiei } \mathrm{F} & \text { Mean } & \text { Polyethylene } \\ 2013^{21} & \text { age }= & \text { ribbon fibers } \\ & 4.2 & \text { followed by } \\ & \text { years } & \text { composite resin }\end{array}$

Retention and marginal adaptation at 1,6 and 12 months

Retention, recurrent caries and the presence of any periapical radiolucency at 6 , 12 and 24 months

Modified Ryge criteria every 6 months for 30 months
In two patients although the restorations The technique for were intact, the endodontic procedure was restoring primary considered to have failed. anterior teeth was By the 18 -month recall, $81.2 \%$ teeth simple, quick and were available for examination and of effective. these there was complete retention of the restorations on $79.9 \%$ of the teeth.

Clinical performance of biological post The biological restoraand crown restorations and intracanal tion presented as a reinforced composite restorations was cost-effective, cliniciancomparable with respect to shade match, friendly, less-technique marginal discoloration, marginal integrity, sensitive and esthetic surface finish, gingival health, retention, alternative to commerand recurrent carious lesions. cially available restorative materials used for restoring grossly carious deciduous teeth.

Fiber glass posts showed better retention Glass fiber posts show and marginal adaptation than omega- better retention and shaped stainless steel wire posts. marginal adaptation than omega-shaped stainless steel wire posts.

The failure rates after 12 and 24 months The modified omega were $10.8 \%$ and $18.5 \%$ respectively. The loop is an efficient primary canines exhibited minimum loss technique. The ease of the restorative material. Two teeth of manipulation and exhibited pathological mobility after short chairside time 2 years. There were not any signs of root are further advanfracture or recurrent caries in any of the tages of the technique. restored teeth.

The surface textures for most of the res- Polyethylene fiber torations were judged as excellent. There posts along with was no evidence of significant changes in extensive composite marginal integrity. Most restored incisors restorations showed $(81 \%)$ received an Alpha rating for reten- excellent clinical tion. The baseline and recall retention performance. scores differed significantly $(p=0.002)$. 
Table 4: Studies excluded from systematic analysis

\begin{tabular}{ll}
\hline Author and year & Reason for exclusion \\
\hline Judd et al $\left(1990^{5}\right)$ & Absence of control group \\
Sharaf $\left(2002^{15}\right)$ & Absence of control group \\
Mortada and King $\left(2004^{6}\right)$ & Absence of control group \\
Aminabadi and Farahani $\left(2009^{10}\right)$ & Absence of control group \\
Memarpour and Shafiei $\left(2013^{21}\right)$ & Absence of control group \\
\hline
\end{tabular}

translucency of composite resin. On the contrary, wire/ metal posts may exhibit greyish translucency due to color of wire not being masked completely by overlying resin. Another advantage is easy technique. However, with composite resin posts there is always an inherent risk of loss of retention owing to polymerization shrinkage. ${ }^{5,32}$

Polyethylene ribbond fiber posts: Ribbond fiber posts offer good impact strength to composite resin used for coronal reconstruction. This is because of their modulus of elasticity and flexural strength being close to dentine. ${ }^{17,18,33}$ Another advantage offered is better adhesion to composite resin matrix when compared to glass fiber posts. ${ }^{34}$ The excellent translucency offers satisfactory esthetics. Best reason for selection of ribbond fiber posts is ease of insertion and when used with flowable composites they conform to shape of root canal.

Omega wire posts: Wire extensions bent in different shapes, i.e. alpha, ${ }^{35}$ gamma ${ }^{36}$ and delta, ${ }^{37}$ have long been used by many clinicians as posts for primary teeth. Wire bent in alpha shape is pressure bonded inside the root canals and this may lead to stresses in the dentin. Although with wire bent in gamma shape a success rate of $93 \%$ has been reported, ${ }^{36}$ the technique, however, has been rated as being operator dependent. Only disadvantages with this technique is only two point retention obtained and color of wire being visible through overlying resin.

Biologic posts: As discussed above, the prime factors to be borne in mind while selecting the appropriate intracanal posts are biocompatibility, ease of applicability and availability with requirement for lesser chairside time. Dentine post/post with core have all these characteristics and an additional advantage of being inexpensive.

Previously, the dentin posts have been prepared using primary root dentin ${ }^{8,24,25}$ while premolar root dentin can also be used. Latter, being the most common tooth extracted for orthodontic reasons, are widely available, while former have a limited availability. Another advantage of using the premolar root pieces is ease of finding them in sound form, while it is difficult to get primary root dentine free from resorption.

One of the limitations of using biologic restorations is preoperative preparation, such as sterilization and preparation of natural tooth to make dentine post/post and core/shell crown. But, these steps can be performed
Table 5: Quality assessment of included studies

\begin{tabular}{|c|c|c|}
\hline Evaluation criteria & $\begin{array}{l}\text { Grewal and } \\
\text { Seth }\left(2008^{8}\right)\end{array}$ & $\begin{array}{l}\text { Subramaniam } \\
\text { et al }\left(2008^{9}\right)\end{array}$ \\
\hline \multicolumn{3}{|l|}{ Definition of inclusion criteria } \\
\hline \multicolumn{3}{|l|}{ Definition of exclusion criteria } \\
\hline \multicolumn{3}{|l|}{ Randomization } \\
\hline \multicolumn{3}{|l|}{ Sequence generation } \\
\hline \multicolumn{3}{|l|}{ Allocation concealment } \\
\hline \multicolumn{3}{|l|}{ Blinding } \\
\hline \multicolumn{3}{|l|}{ Blinding of outcome assessor } \\
\hline \multicolumn{3}{|l|}{ Incomplete outcome reporting } \\
\hline \multicolumn{3}{|l|}{ Reporting of drop outs } \\
\hline \multicolumn{3}{|l|}{$\begin{array}{l}\text { Elaboration of clinical } \\
\text { assessment methods }\end{array}$} \\
\hline \multicolumn{3}{|l|}{$\begin{array}{l}\text { Elaboration of radiographic } \\
\text { assessment methods }\end{array}$} \\
\hline Adequate follow-up period & & \\
\hline
\end{tabular}

Low risk of bias: ; ; High risk of bias: $\square$; Unclear risk of bias

by dental auxiliaries also, and the dentist does not need to spare time for this.

Some parents may find this technique objectionable and inacceptable. However, after counseling and assurance by pediatric dentist about harmless nature of this restorative modality, this problem can be resolved easily.

Indirect composite resin posts: Previously, few authors have reported restoring grossly broken down anterior teeth by indirect technique using various types of posts, such as preformed Ni-Cr posts, ${ }_{1}^{11}$ fiberglass posts ${ }^{12-14}$ and ribbond ${ }^{17}$ as intracanal reinforcement. All of the above listed methods require longer chairside time which may compromise the cooperation by young child with short attention span and little patience. Instead of this usual two step technique, composite crown and post can be fabricated as a single unit by indirect method, thus, saving the chairside time.

Direct composite restorations have been associated with marginal microleakage following polymerization shrinkage, especially at the cervical cavosurface margins, ${ }^{38}$ improper contact points ${ }^{39}$ and relatively low wear resistance. ${ }^{40}$ Extraoral improved curing of the composite resin ${ }^{39}$ can minimize above-mentioned disadvantages of direct composite restorations.

Specific systems though available for laboratory processed indirect composites have little use for primary teeth. The commercially available indirect systems have greater filler loading for improved mechanical strength and better handling properties, these pose a greater economic burden owing to higher cost. Further, these systems were developed for permanent teeth which have a much longer time period to serve in oral cavity than primary teeth. The direct composite material being routinely used for direct restorative procedures may also 
be used and this may be cured with same light cure unit being routinely used for direct composite restorations. Apart from economic advantage, another benefit with direct composite material is that it promises to wear at a rate synonymous with primary teeth.

From above discussion, it becomes clear that further trials with well-defined methodology to eliminate any bias are needed. Currently, the evidence is lacking to provide any recommendation about any method of intracanal reinforcement. The criteria to select method of intracanal reinforcement, i.e. type of posts to restore grossly mutilated teeth are biocompatibility, ease of availability and applicability, esthetics, ability to withstand masticatory forces and ability to allow uninterrupted eruption of permanent successors.

The choice of type of post and/or technique should be based on clinical condition of tooth to be restored, finances and operator as well as patient and/or parent's preference.

\section{CONCLUSION}

1. The evidence to support any method of intracanal reinforcement for restoring grossly broken down anterior teeth is presently lacking.

2. Further, trials with well-defined methodology should be conducted keeping in mind 'The Cochrane Collaboration's tool for assessing risk of bias' and 'CONSORT statement'.

3. The choice of type of post and/or technique is based on clinical condition of tooth to be restored, finances and operator as well as patient and/or parent's preference.

\section{REFERENCES}

1. Lauris JR, da Silva Bastos R, de Magalhaes Bastos JR. Decline in dental caries among 12-year-old children in Brazil, 19802005. Int Dent J 2012;62(6):308-314.

2. Marthaler TM. Changes in dental caries 1953-2003. Caries Res 2004;38(3):173-181.

3. Goyal A, Gauba K, Chawla HS, Kaur M, Kapur A. Epidemiology of dental caries in Chandigarh school children and trends over the last 25 years. J Ind Soc Pedod Prev Dent 2007;25(3):115-118.

4. Mendes FM, De Benedetto MS, Zardetto CGC, Wanderley MT, Correa MSNP. Resin composite restoration in primary anterior teeth using short-post technique and strip crowns: A case report. Quintessence Int 2004;35(9):689-692.

5. Judd PL, Kenny JD, Johnston DH, Yacobi R. Composite resin short-post technique for primary anterior teeth. J Am Dent Assoc 1990;120(5):553-555.

6. Mortada A, King NM. A simplified technique for the restoration of severely mutilated primary anterior teeth. J Clin Pediatr Dent 2004;28(3):187-192.
7. Usha M, Deepak V, Venkat S, Gargi M. Treatment of severely mutilated increases: A challenge to the pedodontist. J Ind Soc Pedodon Prev Dent 2007;25(suppl):34-37.

8. Grewal N, Seth R. Comparative in vivo evaluation of restoring severely mutilated primary anterior teeth with biological post and crown preparation and reinforced composite restoration. J Ind Soc Pedod Prev Dent 2008;26(4):141-148.

9. Subramaniam P, Babu KL, Sunny R. Glass fiber reinforced composite resin as an intracanal post—a clinical study. J Clin Pediatr Dent 2008;32(3):207-210.

10. Aminabadi NA, Farahani ZRM. The efficacy of a modified omega wire extension for the treatment of severely damaged primary anterior teeth. J Clin Pediatr Dent 2009;33(4):283-288.

11. Wanderley MT, Ferreira SL, Rodrigues CR, Rodrigues Filho LE. Primary anterior tooth restoration using posts with macroretentive elements. Quintessence Int 1999;30(6):432-436.

12. Motisuki C, Santos-Pinto L, Giro EMA. Restoration of severely decayed primary incisors using indirect composite resin restoration technique. Int J Peditr Dent 2005;15(4):282-286.

13. Metha D, Gulati A, Basappa N; Raju OS. Esthetic rehabilitation of severely decayed primary incisors using glass fiber reinforced composite: a case report pp. J Dent Child 2012;79(1):22-25.

14. Verma L, Passi S. Glass fibre-reinforced composite post and core used in decayed primary anteriorteeth: a case report. Case Rep Dent 2011;2011:864254.

15. Sharaf AA. The application of fiber core posts in restoring badly destroyed primary incisors. J Clin Pediatr Dent 2002; 26(3):217-224.

16. Viera CL, Ribeiro CC. Polyethylene fiber tape used as a post and core in decayed primary anterior teeth: a treatment option. J Clin Pediatr Dent 2001;26(1):1-4.

17. Rocha RO, das Neves LT, Marotti NR, Wanderley MT, Correa MS. Intracanal reinforcement fiber in pediatric dentistry: a case report. Quintessence Int 2004;35(4):263-268.

18. Bayrak S, Tunc ES, Tuloglu N. Polyethylene fiber-reinforced composite resin used as a short post in severely decayed primary anterior teeth: a case report. Oral Surg Oral Med Oral Pathol Oral Radiol Endod 2009;107(5):e60-e64.

19. Jain M, Singla S, Bhushan B, Kumar S, Bhushan A. Esthetic rehabilitation of anterior primary teeth using polyethylene fiber with two different approaches. J Ind Soc Pedod Prev Dent 2011;29(4):327-332.

20. Chaudhary V, Shrivastava B, Bhatia HP, Aggarwal A, Singh AK, Gupta N. Multifunctional Ribbond-a versatile tool. J Clin Pediatr Dent 2012;36(4):325-328.

21. Memarpour M, Shafiei F. Restoration of primary anterior teeth using intracanal polyethylene fibers and composite: an in vivo study. J Adhes Dent 2013;15(1):85-91.

22. Eshghi A, Esfahan RK, Khoroushi M. A simple method for reconstruction of severely damaged primary anterior teeth. Dent Res J 2011;8(4):221-225.

23. Rallan M, Rallan NS,Navit P, Malhotra G. Modified intracanal post for severely mutilated primary anterior teeth. BMJ Case Reports 2013 Apr 18.

24. Ramires-Romito ACD, Wanderley MT, Oliveira MD, Imparato JC, Correa MS. Biologic restoration of primary anterior teeth. Quintessence Int 2000;31(6):405-411.

25. M Kindly change the reference number 25 to: Mittal NP. Restoring the smile: Inexpensive biologic restorations. Dental Res J (Ishan) 2014;11(3):415-421. 
26. Higgins JPT, Green S. Cochrane Handbook for Systematic Reviews of Interventions Version 5.1.0 [updated March 2011]. The Cochrane Collaboration, 2011. Available at: www. cochrane-handbook.org.

27. Kunz R, Vist G, Oxman AD. Randomisation to protect against selection bias in healthcare trials (Cochrane Methodology Review). In: The Cochrane Library, Issue 1; 2003.

28. Chalmers 1983. Chalmers TC, Celano P, Sacks HS, Smith H. Bias in treatment assignment in controlled clinical trials. $\mathrm{N}$ Engl J Med 1983;309(22):1358-1361.

29. Schulz 1995. Schulz KF, Chalmers I, Hayes RJ, Altman D. Empirical evidence of bias. J Am Med Assoc 1985;273(5): 408-412.

30. Colditz 1989. Colditz GA, Miller JN, Mosteller F. How study design affects outcomes in comparison of therapy. Stat Med 1989;8(4):441-454.

31. Schulz FK, Altman GD, Mother D. CONSORT 2010 Statement: Updated Guidelines for Reporting Parallel Group Randomized Trials. Ann Intern Med 2010;152(11):1-8.

32. Qualtrough AJ, Mannocci F. Tooth-colored post systems: a review. Oper Dent 2003;28(1):86-91.

33. Gurbuz T, Sengul F, Altun C. Finite element stress analysis of short-post core and over restorations prepared with different restorative materials Dent Material J 2008;27(4): 499-507.

34. Vitale MC, Caprioglio C, Martignone A, Marchesi U, Botticelli AR. Combined technique with polyethylene fibres and composite resins in restoration of traumatized anterior teeth. Dent Traumatol 2004;20(3):172-177.

35. Issao M, Guedes-Pints AC. Pediatric Dentistry Manual. 1st ed. Sao Paulo: Pancast; 1978. p. 132-134.

36. Pithan S, Vieira RS, Chain MC. Tensile bond strength of intracanal posts in primary anterior teeth: an in vitro study. J Clin Pediatr Dent 2002;27(1):35-40.

37. Rifkin AJ. Composite post-crowns in anterior primary teeth. J Dent Assoc S Afr 1983;38(4):225-227.

38. Shortall AC, Baylis RL, Baylis MA, Grundy JR. Marginal seal comparisons between resin-bonded Class II porcelain inlays, posterior composite restorations, and direct composite resin inlays. Int J Prosth 1989;2(3):217-221.

39. Burke FJ, Watts DC, Wilson NHF, Wilson MA. Current status and rationale for composite inlays and onlays. Br Dent J 1991; 170(7):269-273.

40. Yap AU, Ong LF, Teoh SH, Hastings GW. Comparative wear ranking of dental restoratives with the BIOMAT wear simulator. J Oral Rehabil 1999;26(3):228-235. 